DOI: https://doi.org/10.24867/12BE16Stefanovic

\title{
ENERGETSKI TRANSFORMATORI U USTALJENIM SLOŽENOPERIODIČNIM REŽIMIMA
}

\section{POWER TRANSFORMERS IN PERIODIC NON-SINUSOIDAL STEADY STATES}

\author{
Nina Stefanović, Dejan Jerkan, Fakultet tehničkih nauka, Novi Sad
}

\section{Oblast - ELEKTROTEHNIKA I RAČUNARSTVO}

Kratak sadržaj - U radu je razvijen matematički model trofaznog, dvonamotajnog energetskog transformatora sprege Dyn5, podesan za proračune ustaljenih složenoperiodičnih režima. Model obezbeđuje uvažavanje postojanja nenultog sprežnog broja transformatora, omogućavajući proračune ustaljenih složenoperiodičnih radnih režima uz istovremeno prisustvo nesimetrije i/ili neuravnoteženosti. Na ilustrativnim primerima je pokazano kakav je uticaj energetskih transformatora na uspostavljanje složenoperiodičnih režima usled harmonijskog izobličenja napona napajanja na njegovim primarnim priključcima.

Ključne reči: Energetski transformatori, Složenoperiodični režimi, Furijeova analiza, MATLAB Simulink

Abstract The paper presents a mathematical model of a three-phase, two-winding power transformer with Dyn5 connection, suitable for calculations of non-sinusoidal periodic steady states. The model ensures that the existence of a non-zero vector group number of transformers is taken into account, enabling calculations of periodic steady states with the simultaneous presence of asymmetry and/or imbalance. Illustrative examples show the influence of power transformers on the establishment of non-sinusoidal periodic states due to the harmonic distortion of the supply voltage at its primary connections.

Keywords: Power transformers, Periodic non-sinusoidal regimes, Fourier analysis, MATLAB Simulink

\section{UVOD}

Energetski transformatori su jedni od najznačajnijih elemenata $\mathrm{u}$ elektroenergetskom sistemu (EES). Na putu pretvaranja energije od njenih primarnih izvora u konvencionalnim elektranama, preko visokonaponske prenosne mreže, pa sve do potrošača na niskom naponu, električna energija biva transformisana $\mathrm{u}$ nekoliko stepena, posredstvom energetskih transformatora. Smisao primene transformatora jeste energetski efikasan prenos električne energije, transformisanjem naponskih nivoa na kojima se određena količina električne energije ekonomski najisplativije prenosi i distribuira. Usled sveprisutnosti transformatora za očekivati je da je njihov uticaj na uspostavljanje radnih režima EES-a veoma značajan,

\section{NAPOMENA:}

Ovaj rad proistekao je iz master rada, čiji mentor je bio dr Dejan Jerkan, docent. ali i da se zbog toga nužno i sami transformatori mogu naći u raznim uslovima, često nedopustivim i nepovoljnim. Pored tipičnih trajno nedozvoljenih pogonskih stanja, poput pojave preopterećenja, previsokih napona ili kratkih spojeva, u poslednje vreme, a ponajviše usled povećane upotrebe nelinearnih elemenata u EES-u, dolazi do pojačane izloženosti energetskih transformatora složenoperiodičnim radnim režimima. Tema ovog rada upravo predstavlja razvoj matematičkog modela energetskog transformatora, koji na pravilan način uvažava uspostavljanje složenoperiodičnih režima uzimajući u obzir osobenosti trofaznih dvonamotajnih energetskih transformatora, uključujući i postojanje nenultog sprežnog broja. Budući da je pojam sprežnog broja, kao i premise pod kojima se on definiše vezan za rad transformatora u ustaljenim i simetričnim prostoperiodičnim režimima direktnog redosleda, izvršiće se odgovarajuća matematička generalizacija pomoću koje će se modeli transformatora za ustaljene prostoperiodične režime prevesti u odgovarajuće modele za proračun ustaljenih složenoperiodičnih režima, uz dopuštenu istovremenu pojavu nesimetrije i/ili neuravnoteženosti.

\section{MODEL TROFAZNOG DVONAMOTAJNOG TRANSFORMATORA}

Model se zasniva na principu Teorije električnih kola, poznatom kao princip superpozicije, koji podrazumeva linearnost elementa čiji se radni režim želi rekonstruisati, tako da će razvijeni model biti u mogućnosti da pravilno uvaži uticaj koji složenoperiodični režimi imaju na energetske transformatore i obratno, ali samo u slučaju da sam transformator nije uzročnik njihovom nastanku.
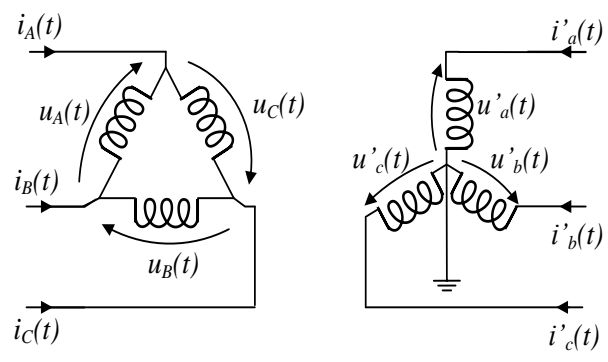

Slika 2.1. Principska šema dvonamotajnog transformatora sprege Dynk

Na slici 2.1 prikazana je principska šema trofaznog, dvonamotajnog transformatora sprege Dynk, gde $k$ predstavlja sprežni broj transformatora, koji za raznorodne sprege može poprimiti bilo koju vrednost iz skupa $\{1,3,5,7,9$, 11\}. Velikim slovima $A, B$ i $C$ u indeksu označeni su 
naponi i struje na njegovim višenaponskim, dok su malim slovima $a, b$ i $c$ označeni naponi i struje na niženaponskim priključcima. Izabrano je modelovanje transformatora ovog tipa sprege, jer je on po pravilu najčešći u eksploataciji u distributivnim mrežama, a u kojima je ujedno i dominantno zastupljena pojava složenoperiodičnih režima.

Ukoliko se transformator nalazi $\mathrm{u}$ ustaljenom prostoperiodičnom režimu, za njega je moguće izvesti matrični model u kompleksnom domenu, gde svaka od dvanaest terminalnih veličina (po šest napona i struja) biva reprezentovana svojim kompleksnim predstavnikom. Ne umanjujući opštost razmatranja, na dalje će se razmatrati transformator sprežnog broja $k=5$.

Matrični model u faznom domenu, kojim se uspostavlja linearna veza između kompleksnih predstavnika dvanaest terminalnih veličina transformatora sprege Dyn 5 prikazan je relacijom 1 :

$$
\left[\begin{array}{l}
I_{h A} \\
\underline{I}_{h B} \\
I_{h C} \\
\underline{I}_{h a}^{\prime} \\
\underline{I}_{h b}^{\prime} \\
I_{h c}^{\prime}
\end{array}\right]=\left[\begin{array}{cccccc}
\frac{2 \underline{Y}_{h}{ }^{d}}{3} & -\frac{\underline{Y}_{h}{ }^{d}}{3} & -\frac{\underline{Y}_{h}{ }^{d}}{3} & \frac{\underline{Y}_{h}{ }^{d}}{\sqrt{3}} & 0 & -\frac{\underline{Y}_{h}{ }^{d}}{\sqrt{3}} \\
-\frac{\underline{Y}_{h}{ }^{d}}{3} & \frac{2 \underline{Y}_{h}{ }^{d}}{3} & -\frac{\underline{Y}_{h}{ }^{d}}{3} & -\frac{\underline{Y}_{h}{ }^{d}}{\sqrt{3}} & \frac{\underline{Y}_{h}{ }^{d}}{\sqrt{3}} & 0 \\
-\frac{\underline{Y}_{h}{ }^{d}}{3} & -\frac{\underline{Y}_{h}{ }^{d}}{3} & \frac{2 \underline{Y}_{h}{ }^{d}}{3} & 0 & -\frac{\underline{Y}_{h}{ }^{d}}{\sqrt{3}} & \frac{\underline{Y}_{h}{ }^{d}}{\sqrt{3}} \\
-\frac{\underline{Y}_{h}{ }^{d}}{\sqrt{3}} & \frac{\underline{Y}_{h}{ }^{d}}{\sqrt{3}} & 0 & -\underline{Y}_{h}{ }^{d} & 0 & 0 \\
0 & -\frac{\underline{Y}_{h}{ }^{d}}{\sqrt{3}} & \frac{\underline{Y}_{h}{ }^{d}}{\sqrt{3}} & 0 & -\underline{Y}_{h}{ }^{d} & 0 \\
\frac{\underline{Y}_{h}{ }^{d}}{\sqrt{3}} & 0 & -\frac{\underline{Y}_{h}{ }^{d}}{\sqrt{3}} & 0 & 0 & -\underline{Y}_{h}{ }^{d}
\end{array}\right]\left[\begin{array}{l}
\underline{U}_{h A} \\
\underline{U}_{h B} \\
\underline{U}_{h C} \\
\underline{U}_{h a}^{\prime} \\
\underline{U}_{h b}^{\prime} \\
\underline{U}_{h c}^{\prime}
\end{array}\right],
$$

gde $\underline{Y}_{h}{ }^{d}$ predstavlja admitansu direktnog redosleda simetrije za harmonik reda $h$. Prilikom izvođenja relacije je usvojeno da su admitanse sva tri redosleda simetrije međusobno jednake, što u opštem slučaju ne mora biti na snazi. Admitanse direktnog i inverznog redosleda za statičke i uravnotežene elemente po prirodi jesu podjednake, dok za admitansu nultog redosleda to ne mora biti slučaj, jer njena vrednost zavisi od konstrukcije elementa i njegovog statusa prema neutralnoj tački. Izjednačavanje admitansi je u ovom radu izvršeno samo zarad kompaktnijeg zapisa, što ni u čemu ne umanjuje opštost. Admitansa direktnog redosleda simetrije predstavlja recipročnu vrednost impedanse kratkog spoja, koja se često može aproksimirati reaktansom induktivnog karaktera, zanemarivanjem aktivne otpornosti namotaja:

$$
\underline{Y}_{h}{ }^{d}=\frac{1}{R_{k}+j X_{h k}}=\frac{1}{R_{k}+j \omega_{h} L_{k}} \approx \frac{1}{h} \frac{1}{j X_{k}},
$$

gde $R_{k}$ predstavlja aktivnu otpornost kratkog spoja transformatora, a $X_{k}$ reaktansu kratkog spoja na učestanosti osnovnog harmonika. Porastom reda harmonika aproksimacija biva sve preciznija predstava rednih parametara ekvivalentnih šema transformatora. Matrični model se može primeniti, primenom principa superpozicije, u rešavanju složenoperiodičnih režima nametnutih transformatoru, tako što se relacija (1) prilagodi i upotrebi u onoliko različitih prostoperiodičnih podproblema koliko složenoperiodične veličine kojima je transformator izložen ukupno imaju prostoperiodičnih harmonijskih komponenti.

Najpre je potrebno odrediti harmonijski sastav složenoperiodičnih veličina kojima je transformator izložen. Zatim se sve harmonijske komponente čije je prisustvo utvrđeno prevedu u odgovarajuće kompleksne predstavnike, a uz važnu napomenu da prelaskom $\mathrm{u}$ domen kompleksnih predstavnika harmonici na istoj učestanosti čine kompleksni podprostor koji je disjunktan sa ostalim podprostorima koje tvore kompleksni predstavnici harmonika na bilo kojoj drugoj učestanosti.

Nakon uvođenja potrebnog broja disjunktnih kompleksnih podprostora, može se pristupiti njihovom rešavanju, a na osnovu dodatnih relacija kojima se bliže opisuje priroda složenoperiodičnog režima koji se želi rekonstruisati. Postupnim rešavanjem disjunktnih podproblema u kompleksnim podprostorima moguće je izvršiti prevođenje izračunatih kompleksnih predstavnika nepoznatih veličina $\mathrm{u}$ pripadajuće harmonijske komponente u vremenskom domenu, gde se složenoperiodični odzivi zadatog problema dobijaju sabiranjem pojedinačnih harmonika koji pripadaju odgovarajućim terminalnim veličinama. Na taj način je izvršena dosledna primena principa superpozicije, raščlanjivanjem originalnog problema na odgovarajući broj prostoperiodičnih podproblema.

Zbog činjenice da je transformator modelovan kao linearni element, on svojim postojanjem neće dovoditi do stvaranja harmonijskih komponenti kojih nema ni $\mathrm{u}$ jednoj od složenoperiodičnih veličina kojima je izložen, ali svojom prirodom može uticati na to da pojedine harmonijske komponente budu suzbijene, a pojedine čak $\mathrm{i}$ pospešene. Relacija (1) u opštem slučaju ima dvanaest nepoznatih terminalnih veličina, dok je sama relacija šestog reda, na osnovu čega sledi da je neke od veličina potrebno poznavati unapred, ali i da je potrebno uvesti dodatne relacije koje u određenim režimima važe između pojedinih terminalnih veličina, kako bi relacija postala jednoznačno rešiva.

U narednom poglavlju će se razvijeni model koristiti za rekonstruisanje režima u kojima je unapred poznato naponsko pobuđivanje transformatora preko primarnih priključaka, dok će se sa njegove sekundarne strane modelovati različita pogonska stanja, čijim podrobnijim opisivanjem dodatnim relacijama, uz poznavanje napona primarne strane, matrična relacija (1) postaje jednoznačno rešiva za svaki od prostoperiodičnih podproblema.

\section{PRIMENA RAZVIJENOG MODELA TRANSFORMATORA}

Pomoću razvijenog modela se mogu rekonstuisati razni karakteristični radni režimi transformatora, uvođenjem dodatnih relacija kojima se podrobnije opisuje njihova topologija.

Modelu je moguće nametnuti praktično bilo kakve talasne oblike terminalnih veličina, ali će se za potrebe njegove verifikacije usvojiti unapred poznati složenoperiodični talasni oblici napona primara sa harmonijskim sastavom koji se može očekivati u eksploataciji.

Isti harmonijski sastav napona primara će se zatim koristiti za sve radne režime koji će se u ovom poglavlju razmatrati. 


\subsection{Transformator u složenoperiodičnom režimu praznog hoda}

Kao prvi karakteristični radni režim će se rekonstuisati rad transformatora u praznom hodu. Na slici 3.1 je data principska šema modelovanog transformatora $\mathrm{u}$ ovom radnom režimu. Zbog zanemarenja otočnih parametara prilikom izvođenja matematičkog modela, za očekivati je da je svih šest struja unapred poznato i jednako nuli, što upravo predstavlja dodatne relacije topologije razmatranog režima kojima se model upotpunjuje do njegove određenosti, što je i naznačeno na samoj slici 3.1.

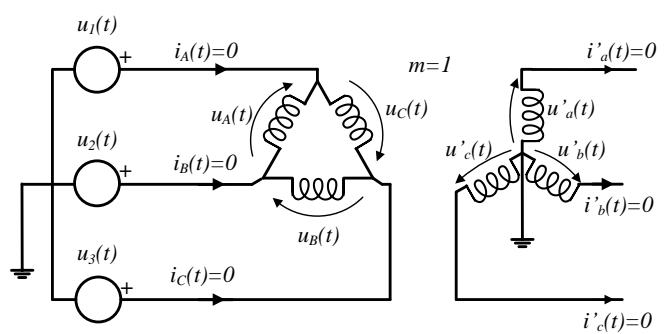

Slika 3.1. Principska šema transformatora u režimu praznog hoda

Idealni naponski izvori napajanja primarne strane su izabrani tako da predstavljaju trojku simetričnih veličina, koje zbog prirode viših harmonika u EES-u imaju isključivo harmonike neparnog reda. Za naponski izvor u fazi $A$ prema tome važi:

$$
u_{1}(t)=\sum_{l=1}^{N} U_{m_{2 l-1}} \cdot \cos \left((2 l-1) \omega_{1} t+\varphi_{0_{2 l-1}}\right),
$$

gde $U_{m_{2 l-1}}$ predstavlja amplitudu harmonika reda $h=(2 l-1), \varphi_{0_{2 l-1}}$ predstavlja fazni stav, $\omega_{1}$ je ugaona učestanost osnovnog harmonika, a $N$ određuje red harmonika. Naponi preostala dva izvora se dobijaju faznim pomeranjem sabiraka u izrazu (3) $\mathrm{za} \pm \frac{2 \pi}{3}(2 l-1)$. Naponi faza primarne strane transformatora se od napona mreže dobijaju oduzimanjem odgovarajućih parova:

$$
\begin{aligned}
& u_{A}(t)=u_{1}(t)-u_{2}(t) \\
& u_{B}(t)=u_{2}(t)-u_{3}(t) \\
& u_{C}(t)=u_{3}(t)-u_{1}(t)
\end{aligned}
$$

Na slici 3.2 je prikazan amplitudni spektar napona faze $A$ primara $\mathrm{u}$ relativnim jedinicama, koji je dobijen na osnovu napona $u_{1,2,3}(t)$ u kojima amplituda harmonika opada obrnuto proporcionalno njihovom redu, dok je za početni fazni stav svakog od harmonika uzeta nulta vrednost.
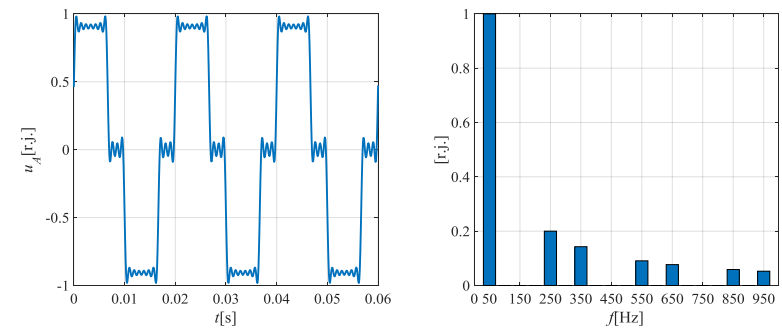

Slika 3.2. Napon faze A primara i njegov amplitudni spektar

Na slici 3.3 su prikazani naponi primara za faze $A, B$ i $C$, kao i fazni spektar faza $B$ i $C$.
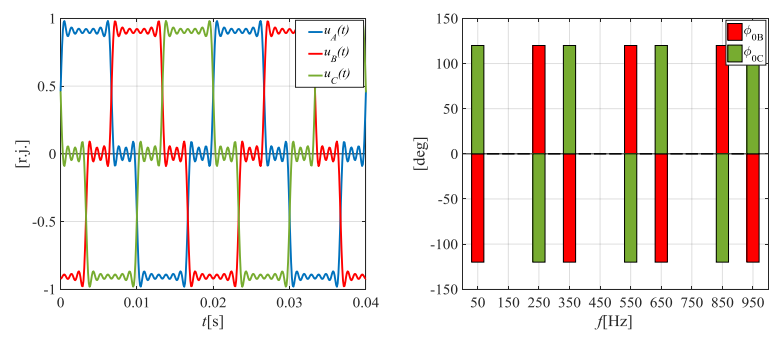

Slika 3.3. Talasni oblici napona faza A, B i C, kao i fazni spektarfaza $B$ i $C$

Uz zadati profil napona primara i unapred poznate struje $u$ režimu praznog hoda, primenom relacije (1) za svaki red harmonika ponaosob se mogu dobiti nepoznati naponi sekundara, postupnim rešavanjem odgovarajućeg broja matričnih relacija (1), a zatim vraćanjem dobijenih kompleksnih predstavnika u vremenski domen i njihovim sumiranjem.

$\mathrm{Na}$ slici 3.4 su uporedo prikazani ovim postupkom dobijeni talasni oblici napona sekundara, kao i njihov amplitudni spektar u relativnim jedinicama.
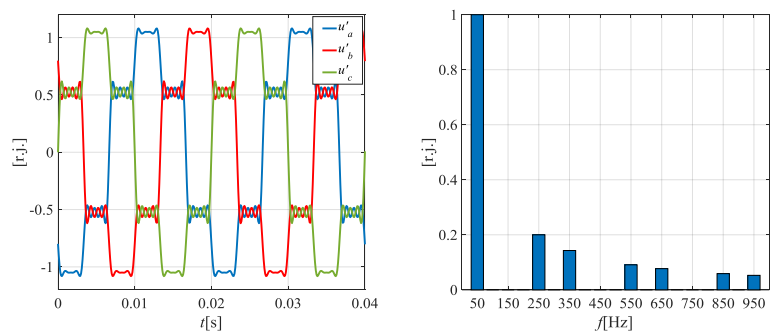

Slika 3.4. Talasni oblici napona faza a, b i c, kao i njihov amplitudni spektar

Mada naponi sekundara imaju isti amplitudni spektar kao i oni sa primarne strane, primećuje se da su im talasni oblici potpuno drugačiji. Ovo se duguje činjenici da model transformatora uvažava nenulti sprežni broj, koji vrši fazno pomeranje veličina sa primarne strane za $5 \times 30^{\circ}=150^{\circ}$ za harmonike reda $6 l+1$, odnosno pomeranje za $-5 \times 30^{\circ}=-150^{\circ}$ za harmonike reda $6 l+1$, što je u potpunosti u skladu sa osobinama viših harmonika neparnog reda koje se imaju u eksploataciji realnog EES-a.

Na slici 3.5 su uporedo prikazani talasni oblici napona faze $A$ primara i napona faze $a$ sekundara, kao i spektar faznih pomeraja odgovarajućih parova njihovih harmonijskih komponenti, kojim se potvrđuje da razvijeni model na pravilan način uvažava postojanje nenultog sprežnog broja i njegov uticaj na talasne oblike napona sekundara u odnosu na primarne napone.
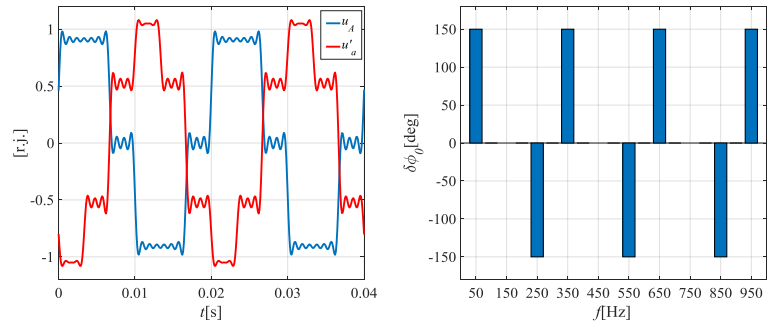

Slika 3.5. Uporedni prikaz napona faze A i a, kao i spektar faznih razlika njihovih harmonijskih komponenti 


\subsection{Transformator u složenoperiodičnom režimu tropolnog zemljospoja}

Kao drugi primer primene modela će se izvršiti proračun ustaljenog složenoperiodičnog režima izazvanog pojavom tropolnog zemljospoja na transformatorskim sekundarnim priključcima. Kao izvori napajanja će se iskoristiti isti talasni oblici napona definisani relacijama (3) i (4), prikazani slikama 3.2 i 3.3. Tropolni zemljospoj karakterišu unapred poznati fazni naponi sekundara transformatora, koji su identički jednaki nuli, što je na slici 3.6 i naznačeno. Uz poznate talasne oblike napona primarne strane, topologija tropolnog zemljospoja opisana vrednostima napona sekundara čini svaku od matričnih relacija oblika (1) potpuno određenom za rešavanje.

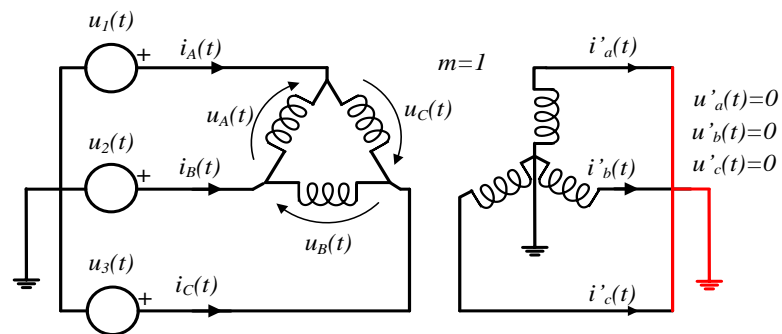

Slika 3.6. Principska šema transformatora u režimu tropolnog zemljospoja

Uz zadati profil napona primara i nulte vrednosti napona sekundara, primenom relacije (1) za svaki red harmonika ponaosob se mogu dobiti nepoznate struje sa oba kraja transformatora, postupnim rešavanjem odgovarajućeg broja matričnih relacija (1), a zatim vraćanjem dobijenih kompleksnih predstavnika u vremenski domen i njihovim sumiranjem. Na slici 3.7 su uporedo prikazani talasni oblici struja primara tokom tropolnog zemljospoja na sekundarnim priključcima, kao i njihov amplitudni spektar. Primetno je da su harmonijske komponente višeg reda manjih relativnih amplituda $\mathrm{u}$ odnosu na one $\mathrm{u}$ amplitudnom spektru napona napajanja, što je u svemu prema očekivanjima i u skladu sa relacijom (2), gde je očito da admitansa transformatora opada sa porastom reda harmonika, suzbijajući uspostavljanje struja viših harmonika.
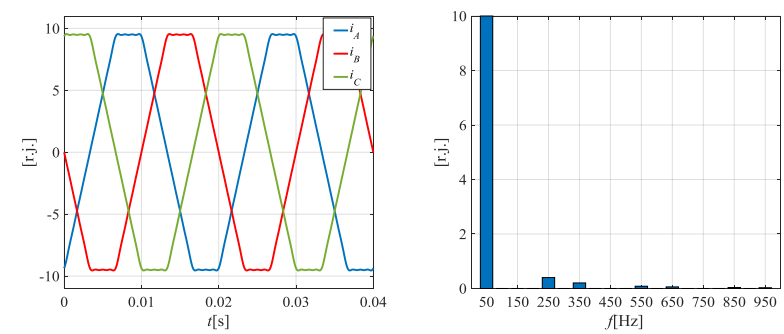

Slika 3.7. Primarne struje tokom tropolnog zemljospoja $i$ njihov zajednički amplitudni spektar

Na slici 3.8 su prikazani talasni oblici sekundarnih struja, kao i njihov amplitudni spektar. Kao što je bio slučaj sa naponima u režimu praznog hoda, tako se i ovde u strujama sa različitih strana transformatora uočava isti amplitudni spektar, a različiti talasni oblici. Ovo je naravno ponovo posledica različitog dejstva nenultog sprežnog broja na harmonijske komponente različitog reda, što se jasno može uočiti na slici 3.8 , gde su uporedo prikazani talasni oblici struja faze $A$ primara i faze $a$ sekundara, kao i spektar razlike faznih stavova njihovih odgovarajućih harmonijskih komponenti.
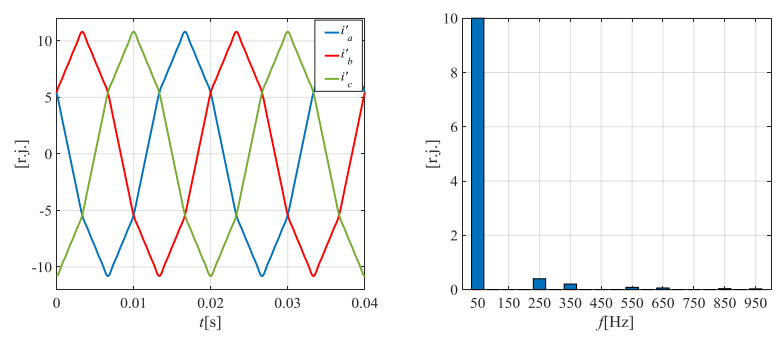

Slika 3.8. Sekundarne struje tokom tropolnog zemljospoja i njihov zajednički amplitudni spektar
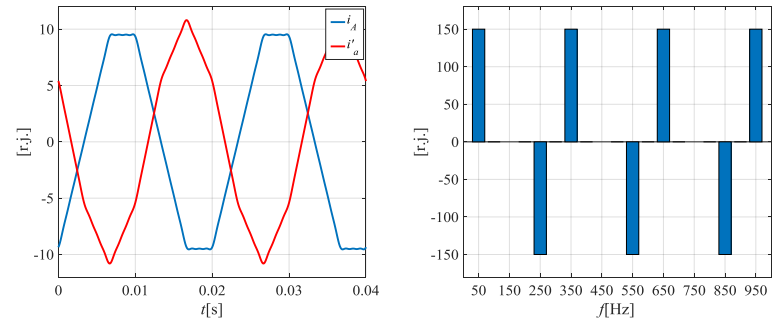

Slika 3.9. Uporedni prikaz struja faze A i a, kao i spektar faznih razlika njihovih harmonijskih komponenti

\section{ZAKLJUČAK}

U radu su izložene teorijske osnove modelovanja trofaznih dvonamotajnih transformatora koje omogućavaju opisivanje njihovog rada u ustaljenim složenoperiodičnim režimima, uz istovremeno prisustvo nesimetrije $\mathrm{i} / \mathrm{ili}$ neuravnoteženosti. Na primeru najčešće korišćenog tipa transformatora u distributivnim mrežama EES-a, sprege Dyn5, razvijeni model je verifikovan u karakterističnim ustaljenim složenoperiodičnim radnim režimima, kao što su režim praznog hoda, odnosno pojava tropolnog zemljospoja neposredno na njegovim sekundarnim priključcima. Prilaganjem rezultata proračuna u vidu talasnih oblika, te amplitudnog i faznog spektra pomoću modela izračunatih terminalnih veličina transformatora se potvrđuje da na pravilan način uvažava premise pod kojima je izveden, te da se može koristiti za rekonstruisanje praktično proizvoljnog složenoperiodičnog režima nametnutog transformatoru.

\section{LITERATURA}

[1] Branimir D. Reljin, „Teorija električnih kola II“" Akademska Misao Beograd, 2009.

[2] R. Ramirez, "The FFT-Fundamentals and Concepts", Prentice-Hall Inc., New Jersey, 1985.

[3] J. Arrillaga, D. Bradley, P.Bodger, "Power System Harmonics", John Wiley \& Sons, Chichester,1985.

[4] Dr ing. Hrvoje Požar, „Visokonaponska rasklopna postrojenja“, Tehnička Misao, Zagreb.

[5] Dipl ing. Branko Mitraković, „Tрансформатори“, Naučna Knjiga, Beograd 1968.

[6] www.mathworks.com

\section{Kratka biografija:}

Nina Stefanović rođena je u Zrenjaninu 1995. god. Master rad na Fakultetu tehničkih nauka iz oblasti Elektrotehnike i računarstva - Distribuirani energetski resursi odbranila je 2020. god.

Dejan Jerkan je docent na Fakultetu tehničkih nauka u Novom Sadu, na Katedri za Energetsku elektroniku i pretvarače. Oblast interesovanja su mu modelovanje i dijagnostika električnih mašina, kao i metoda konačnih elemenata 